\title{
Variations and trends of terrestrial NPP and its relation to climate change in the 10 CMIP5 models
}

\author{
Suosuo $\mathrm{Li}^{1,2, *}$, Shinua Lü ${ }^{1}$, Yuanpu Liu ${ }^{2}$, Yanhong GaO ${ }^{1}$ and Yinhuan $\mathrm{Ao}^{1}$ \\ ${ }^{1}$ Key Laboratory of Land Surface Process and Climate Change in Cold and Arid Regions, Cold and Arid Regions \\ Environmental and Engineering Research Institute, Chinese Academy of Sciences, Lanzhou, Gansu 730000, China. \\ ${ }^{2}$ Key Laboratory of Arid Climatic Change and Reduction Disaster, Gansu Province and Key Laboratory of Arid \\ Climatic Change and Reduction Disaster, CMA, Institute of Arid Meteorology, China Meteorological \\ Administration, Lanzhou, Gansu 730020, China. \\ *Corresponding author.e-mail: liss@lzb.ac.cn
}

Using global terrestrial ecosystem net primary productivity (NPP) data, we validated the simulated multi-model ensemble (MME) NPP, analyzed the spatial distribution of global NPP and explored the relationship between NPP and climate variations in historical scenarios of 10 CMIP5 models. The results show that the global spatial pattern of simulated terrestrial ecosystem NPP, is consistent with IGBP NPP, but the values have some differences and there is a huge uncertainty. Considering global climate change, near surface temperature is the major factor affecting the terrestrial ecosystem, followed by the precipitation. This means terrestrial ecosystem NPP is more closely related to near surface temperature than precipitation. Between 1976 and 2005, NPP shows an obvious increasing temporal trend, indicating the terrestrial ecosystem has had a positive response to climate change. MME NPP has increased 3.647PgC during historical period, which shows an increasing temporal trend of $3.9 \mathrm{gCm}^{-2} \bullet 100 \mathrm{yr}^{-2}$ in the past 150 years, also indicating that the terrestrial ecosystem has shown a positive response to climate change in past 150 years.

\section{Introduction}

Net primary productivity (NPP) is the net amount of dry organic material which is produced by ecosystem's green plants in unit time and area, and is an important variable for global carbon cycle and the feedback between terrestrial ecosystems and atmosphere. NPP reflects the ability of plants absorbing atmospheric carbon dioxide and is a key process of carbon cycle (Cramer et al. 1999; Runing et al. 1999; He et al. 2005; Dan et al. 2007). NPP integrates climatic, ecological, geochemical, and human influences on the biosphere (Nemani et al. 2002, 2003). Spatial and temporal variations in NPP are of great importance to ecological studies, natural resource management, and terrestrial ecosystem carbon sink estimates (Cao et al. 2004).

NPP is highly variable in space and time. Spatial variations of NPP are related to factors such as climate, vegetation distribution, and land use across the planet from local to global scales (Cao et al. 2004). Temporal changes in NPP are linked to seasonal variability, atmospheric composition, climatic change, and so on (Cao et al. 2004). Though modern ecology could get accurate NPP based on experiments, both in laboratory and in field settings, this approach could not obtain measurements on a large scale, such as global or continental. There are two ways to reach this goal. One of them is

Keywords. CMIP5; terrestrial ecosystem; NPP; multi-model ensemble (MME); climate change. 
satellite remote sensing, which could provide large sample sizes. Another is global ecosystem models, which could get a satellite-based estimate of NPP given the variable climate, vegetation distribution, and land use across the planet from local to global scales (Bala et al. 2013).

In recent decades, earth system has experienced changes in the energy, momentum, and water exchange between land surface and atmosphere. These changes have caused significant changes in the vegetation growth processes which are closely linked with the terrestrial ecosystem carbon cycle (Dan et al. 2007). To describe the vegetation growing processes, the dynamical global vegetation models (DGVM) have been developed and validated worldwide. Furthermore, they are coupled with general circulation model (GCM) in one-way or two-way coupling approaches. Many previous analyses and simulations have proven that climate change plays an important role in terrestrial ecosystem. It is necessary to evaluate and validate NPP variation related to climate change from the GCMs (Dan et al. 2007).

The fifth phase of the Coupled Model Intercomparison Project (CMIP5) provides a good platform for coupled model intercomparison research of climate change and terrestrial ecosystem (Taylor et al. 2012). The present study compares and validates terrestrial ecosystem NPP simulated by a selection of CMIP5 models with International Geosphere Biosphere Program (IGBP) NPP data. We analyze changes of NPP, explore the relationship between NPP and climatic factors, and discuss the uncertainty or discrepancy of modelled NPP.

\section{Models and data}

\subsection{Models}

Ten models were employed for the current study (table 1), which have wide range of spatial resolutions and physical parameterization schemes. Regarding land surface processes, every model includes a DGVM, such as AVIM, CoLM, CTEM, CLM-CN (in CLM4, the user runs the CNDV as a DGVM), LPJ, TRIFFID, ORCHIDEE and SEIBDGVM, which is coupled to an atmospheric general circulation model (AGCM). All of these DGVMs have been widely used and evaluated either offline or in coupled model studies (Melillo et al. 1993; Dan et al. 2005, 2007). Specially, three of the 10 models use CLM-CN model, and bcc-csm1-1 and bcc-csm1-1-m have different resolutions but all others are same.

While the selected 10 models contain different DGVM, there are still some similarities in their terrestrial carbon cycle. For example, plants are

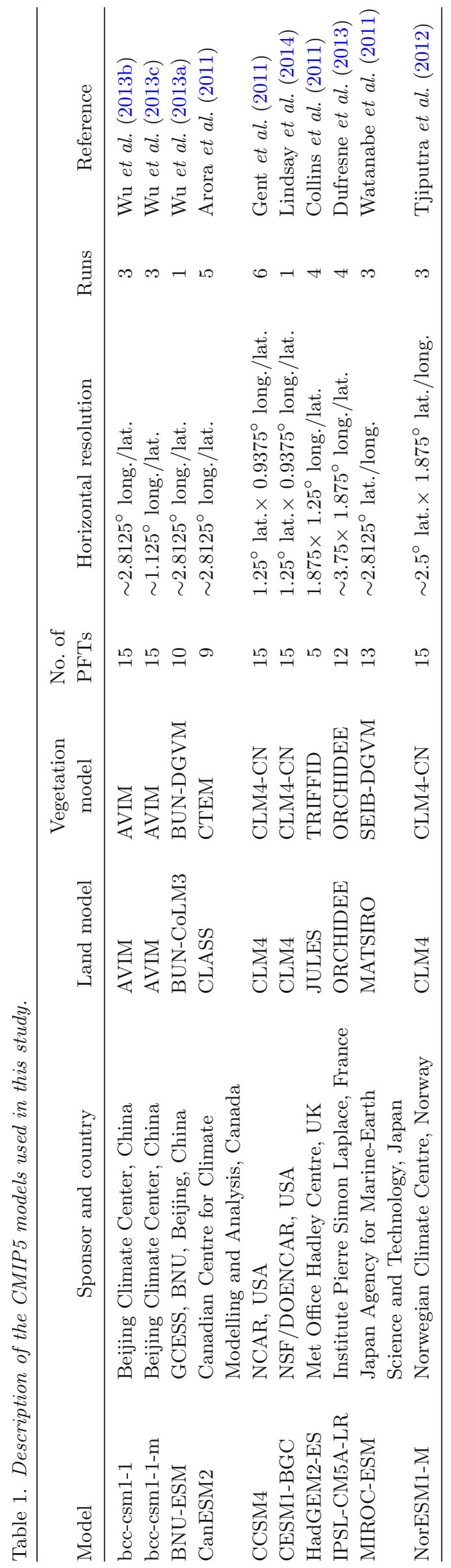


categorized in to several different plant function types (PFTs). For each PFT, the processes of photosynthesis (A), maintenance respiration $(\mathrm{Rm})$ and growth respiration $(\mathrm{Rg})$ carbon allocation are similar across the models, though their specific parameters and limiting conditions are different (Shao et al. 2013). Gross primary production (GPP) is a measure of carbon absorption by vegetation per unit time $(\Delta t)$ and space, which is the aggregate amount of $\mathrm{A}$ at every time step, and net primary production (NPP) is the difference between GPP and autotrophic respiration ( $\mathrm{Ra}$, as the sum of $\mathrm{Rm}$ and $\mathrm{Rg}$ ).

$$
\begin{aligned}
& \mathrm{GPP}=\sum A \Delta t \\
& \mathrm{NPP}=\mathrm{GPP}-\mathrm{Ra}=\mathrm{GPP}-\mathrm{Rm}-\mathrm{Rg}
\end{aligned}
$$

Overall, DGVMs simulate well the global terrestrial carbon pool sizes and carbon cycle, and capture the biogeographical distribution of Earth's major biomes (Sitch et al. 2003).

Therefore, a GCM-DGVM is a full coupled model, which includes important feedback and responses between biosphere and atmosphere, such that vegetation shifts and changes in the carbon and hydrological cycles affecting climate can be simulated. DGVMs commonly simulate a variety of plant and soil physiological processes. They can reflect the effects and responses of vegetation to climate change and get the actual climate change and changes in the terrestrial ecosystem (Olofsson and Hickler 2008).

\subsection{Data}

IGBP Global NPP Model Intercomparison Data with the resolution of $0.5^{\circ} \times 0.5^{\circ}$, and derived from original data containing gridded average NPP for 17 global biogeochemistry models, are used to evaluate the simulated NPP by CMIP 5 models. Table 2 lists some detailed information for comparing the IGBP NPP models and selected CMIP5 land models. The IGBP NPP models were focused on geosphere and biosphere, 16 of 17 models were offline and without DGVM, and all models were forced by Potsdam Institute of Climate Impact Research (PIK) input data. All selected CMIP5 models were coupled models, which have a DGVM. Fortunately, the 17 models which are selected in this paper are different with the DGVM in GCM. The IGBP NPP data are used widely to compare and validate simulated NPP data (Cramer et al. 1999; Dan et al. 2007).

The simulated terrestrial ecosystem NPP data and climate factors: precipitation $(\mathrm{Pr})$, near surface temperature (Tas), and surface downwelling shortwave radiation (Rsds) were selected from the historical scenarios of the 10 CMIP5 models, using as many runs as possible (for one model, each run differ in the initial conditions), and table 1 provides more detailed information. Firstly, we calculated an average of all the runs for each model, and then produced a multi-model ensemble (MME) for each variable, thus obtaining an MME result for each variable. Many studies have indicated that MME results produce better estimates of the real value than any particular model taken individually (Dan et al. 2007; IPCC 2001, Chapter 9). Therefore, to ensure robust results, the MME results are used in the current analysis.

In climatic research, a popular climatological baseline period is a 30-year 'normal' period, as defined by the WMO, which provides a standard reference for many studies (IPCC 2001, Chapter 3). Herein, we use the period $1976-2005$ as the baseline climatology, and correspondingly, we use the simulated NPP during the same period to research the baseline NPP.

\section{Results}

\subsection{Spatial distribution of global NPP}

The simulated MME NPP (figure 1a) is similar to the IGBP NPP (figure 1b). The highest NPP is in the tropical rainforest region of Africa, southeast Asia, and Amazonia, which is larger than $1100 \mathrm{gCm}^{-2} \mathrm{yr}^{-1}$, while intermediate NPP is located

Table 2. Comparing IGBP NPP models and selected CMIP5 models.

\begin{tabular}{lcc}
\hline & \multicolumn{1}{c}{ IGBP } & CMIP5 (selected) \\
\hline Model & BIOME3, BIOME-BGC, CARAIB2.1, CASA, & AVIM, BNU-DGVM, CTEM, CLM4-CN, \\
& CENTURY4.0, DOLY, FBM2.2, GLO-PEM, & TRIFFID, ORCHIDEE, SEIB-DGVM \\
& HRBM3.0, HYBRID3.0, KGBM, PLAI0.2, & \\
& SDBM, SIB2, SILVAN2.2, TEM4.0, TURC & \\
Coupled/offline & 16 models with offline SIB2 with coupled & All models with coupled \\
DGVM & HYBRID3.0 with DGVM 16 models without DGVM & All models with DGVM (CNDV) \\
Forcing & Potsdam Institute of Climate Impact Research & Solar irradiance, greenhouse gas concentration, \\
& (PIK) input data & CO emissions, anthropogenic aerosols, \\
& & sea salt, dust are recommended by CMIP5 \\
\hline
\end{tabular}




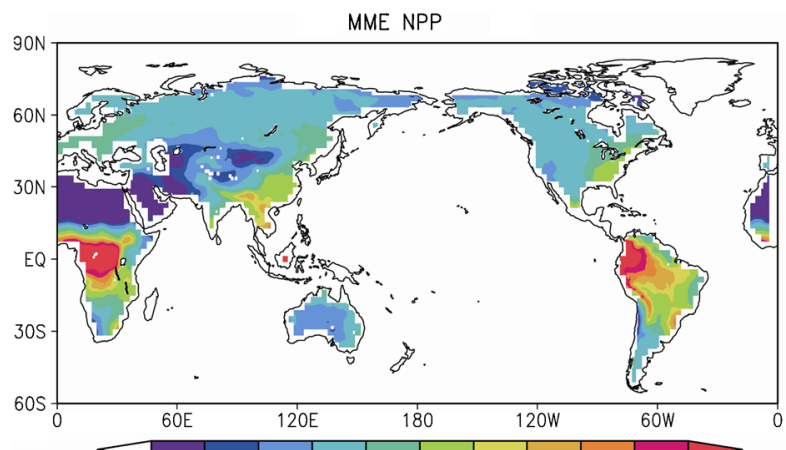

(a)
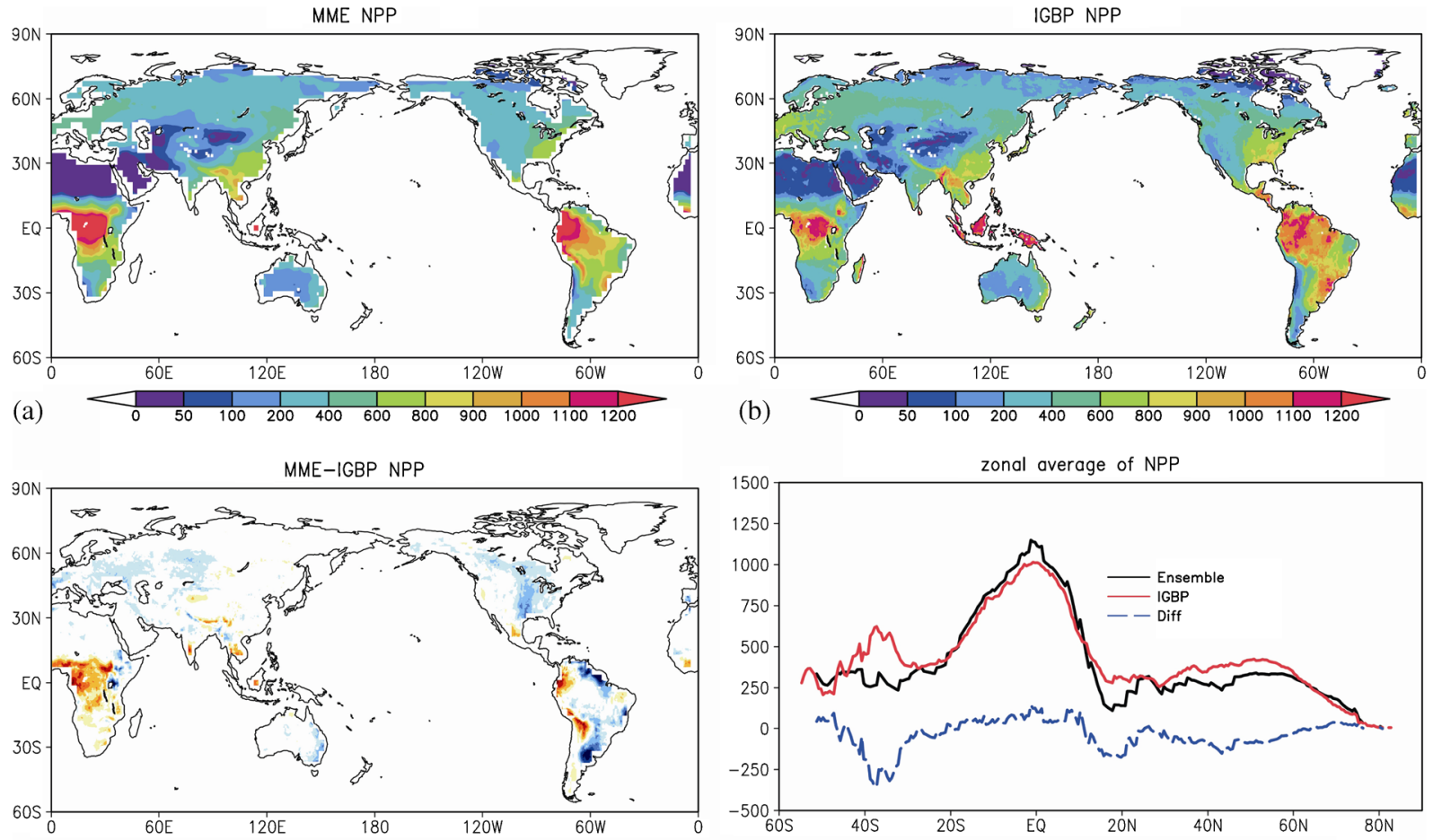

(c)
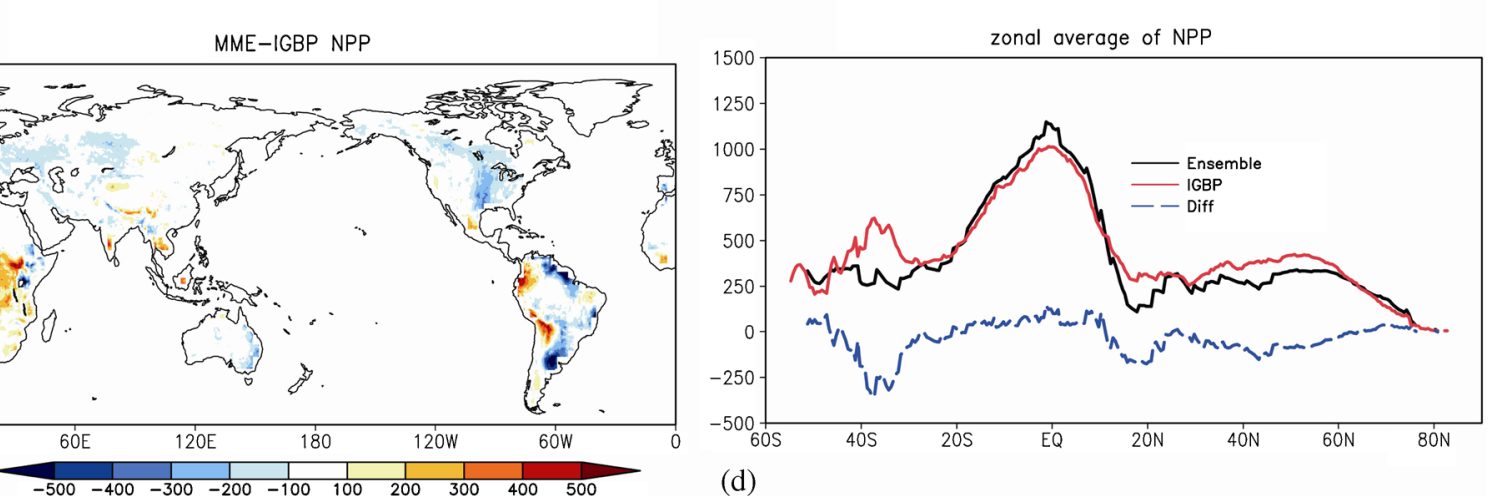

(d)

Figure 1. Global annual mean NPP over land, with unit of $\mathrm{gCm}^{-2} \bullet \mathrm{yr}^{-1}$ (a) MME NPP; (b) IGBP NPP; (c) the difference of NPP between MME and IGBP; and (d) zonal average of annual mean NPP.

Table 3. Area-averaged annual NPP, units are $\mathrm{gCm}^{-2} \mathrm{yr}^{-1}$.

\begin{tabular}{lcccccc}
\hline & Global & $60^{\circ}-30^{\circ} \mathrm{S}$ & $30^{\circ} \mathrm{S}-0$ & $0-30^{\circ} \mathrm{N}$ & $30^{\circ}-60^{\circ} \mathrm{N}$ & $60^{\circ}-90^{\circ} \mathrm{N}$ \\
\hline IGBP & 451.677 & 461.721 & 657.259 & 469.356 & 378.736 & 223.217 \\
Ensemble & 414.873 & 290.415 & 675.664 & 443.614 & 297.348 & 237.798 \\
\hline
\end{tabular}

in temperate regions, and the lowest NPP, which is less than $100 \mathrm{gCm}^{-2} \mathrm{yr}^{-1}$, is in cold or arid areas. The global spatial patterns of MME and IGBP NPP are rather consistent with some other global or regional observation data (Kicklighter et al. 1999; Dan et al. 2007). However, the simulated MME NPP exhibits an obviously higher NPP in the Sahel area and along the west coast of South America, while in the south of India and Asia, there also exists a higher simulated NPP. In most areas of Eurasia and North America, the CMIP5 models obtain a lower MME NPP, and there is also a lower MME NPP along the east coast of South America (figure 1c). Zonal mean NPP shows a similar latitudinal variation pattern despite a different magnitude (figure 1d). The simulated MME NPP is very close to the IGBP NPP, except in $35^{\circ}-30^{\circ} \mathrm{S}$. Generally, between $20^{\circ} \mathrm{S}$ and $15^{\circ} \mathrm{N}$, the simulated MME NPP is larger than the IGBP NPP, while in $45^{\circ}-20^{\circ} \mathrm{S}$ and $15^{\circ}-70^{\circ} \mathrm{N}$, the simulated MME NPP is lower than the IGBP NPP.

Table 3 shows the area-averaged annual IGBP and simulated MME NPP at the global and regional scale. The global-averaged IGBP NPP is
$451.677 \mathrm{gCm}^{-2} \mathrm{yr}^{-1}$, which is almost $55.05 \mathrm{PgC}$ $\mathrm{yr}^{-1}$, and the simulated MME NPP is 414.873657 $\mathrm{gCm}^{-2} \mathrm{yr}^{-1}$, which is almost $50.6 \mathrm{PgC} \mathrm{yr}^{-1}$. Comparing the zonal-averaged IGBP NPP, the largest bias appears over $60^{\circ}-30^{\circ} \mathrm{S}$, which corresponds to the simulated low MME NPP of $35^{\circ}-30^{\circ} \mathrm{S}$. Generally, the simulated MME NPP in the northern hemisphere compares better with IGBP NPP than in the southern hemisphere.

\subsection{Relationship between climate and terrestrial ecosystem NPP}

Many studies have indicated that the terrestrial ecosystem has a strong relationship with climate (Melillo et al. 1993; Ito and Oikawa 2000; Bala et al. 2013). Figure 2 presents the spatial patterns of correlation coefficients between MME NPP and Pr, Tas, and Rsds. Figure 2(a) shows that NPP has a positive correlation with $\mathrm{Pr}$ almost everywhere except in a number of small locations. The highest correlation coefficients, with a greater statistical significance of $99.9 \%$, mainly appear in the north of Russia, Alaska, and Sahel. The correlation 
$\operatorname{Pr}$ and NPP

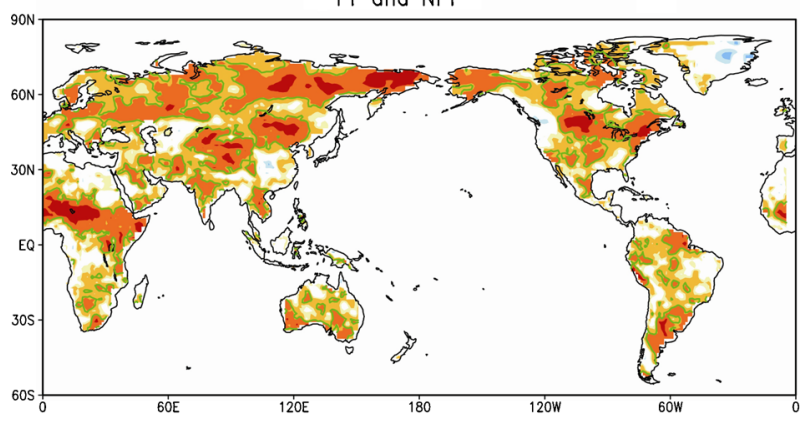

(a)

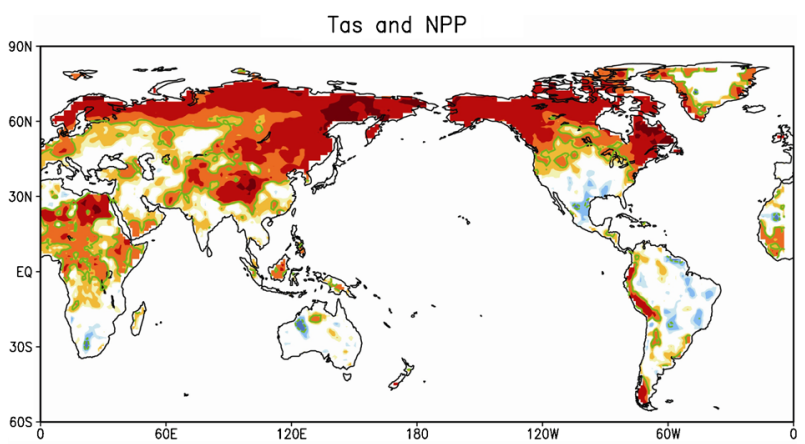

(b)

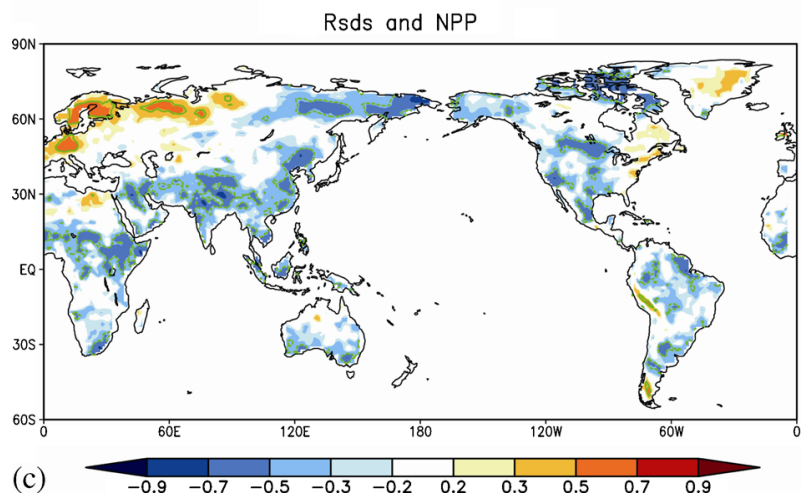

Figure 2. Correlation between annual averaged MME NPP and climate variables MME (a) Pr, (b) Tas and (c) Rsds (green line indicates the correlation coefficients corresponding to the $99 \%$ significance level) during 1976-2005 over global land.

coefficients of NPP with Tas are positive in the northern hemisphere, but in most areas of southern hemisphere, they are negative. The highest positive correlation coefficients appear in the north of Russia and Europe, in the north of America, Sahel area, east of Tibet Plateau, and northeast of China, while the highest negative correlation coefficients appear in the Amazon, west of Brazil, and south of Australia. The correlation coefficients of NPP with Rsds are negative almost everywhere, except in the north of Europe, northwest of Russia and east coast of America. The highest correlation coefficient appears in the east of Russia, south of India, Sahel and north of South America, which is related to the regional climate. For example, in the Sahel region and south of India, the precipitation and temperature are very suitable for plant growth, and the third variable of Rsds is the limiting factor, and so we can get the highest correlation coefficient.

In order to obtain the real relationship between climate and terrestrial ecosystem NPP, we separated the interannual variability from the effects of trends, and subtracted the linear trend and mean from the time series of annual Pr, Tas, Rsds, and NPP. The results still show that NPP has positive correlations with $\mathrm{Pr}$ almost everywhere (figure $3 \mathrm{a}$ ). The correlation coefficients of NPP with Tas are positive in the high latitudes of the northern hemisphere and east Asia, while in most areas of southern hemisphere, they are negative. The
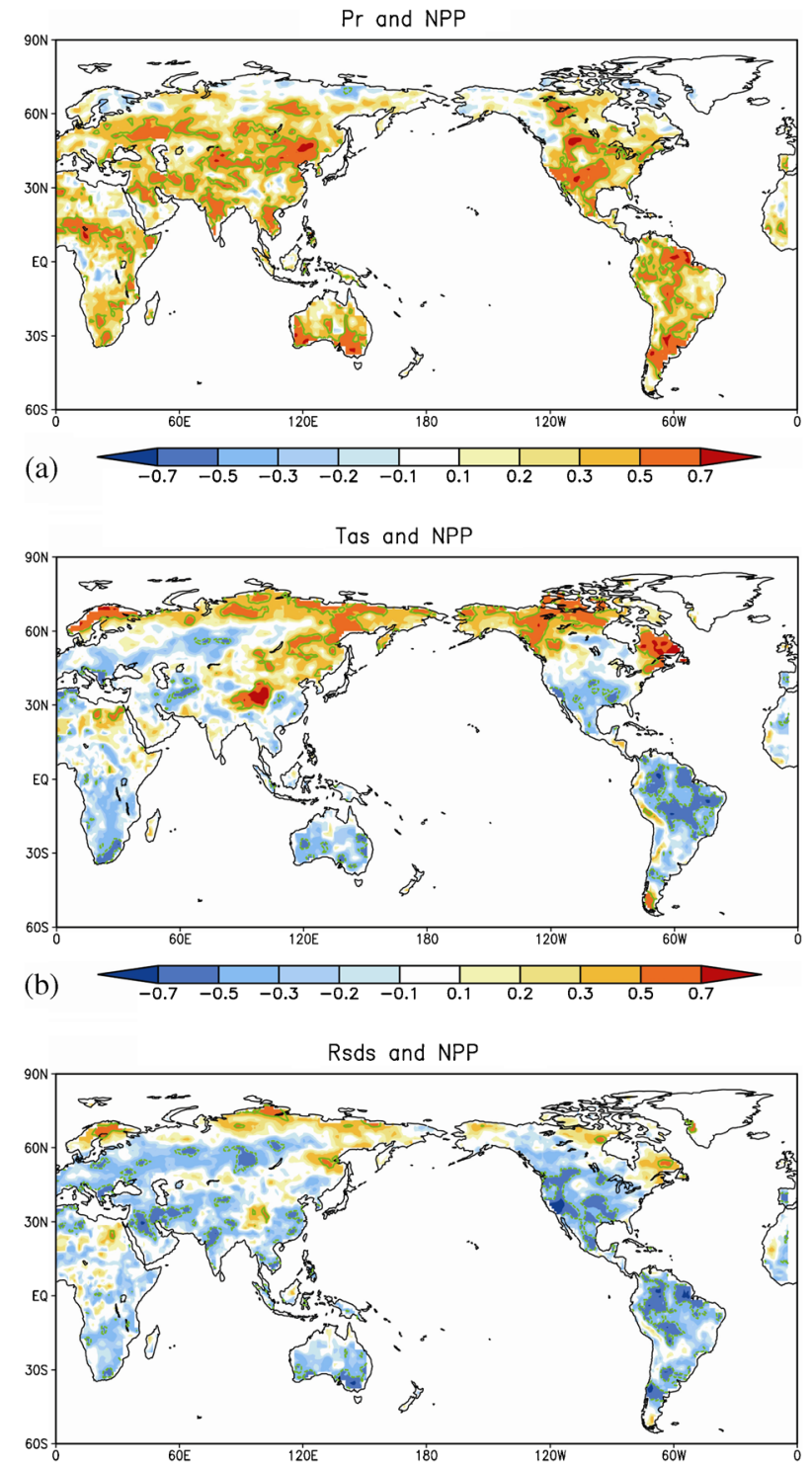

(c)

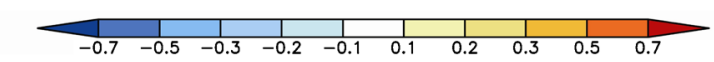

Figure 3. Same as figure 2, but with mean and trend removed. 
correlation coefficients of NPP with Rsds are negative almost everywhere, except the north of Europe, which is very similar with the results presented in figure $2(\mathrm{c})$.

Comparing figures 2 and 3, one can see some obvious differences. The level of correlation is less in figure 3 than in figure 2, because the trend and mean were removed. In figure 2, Pr mainly has a positive correlation coefficient with NPP, and Tas and Rsds mainly have a negative correlation coefficient with NPP. The patterns of correlation coefficient between $\mathrm{Pr}$, Rsds, and NPP (figure 3a, c) are similar to figure 2(a and c), but the pattern of correlation coefficient between Tas and NPP (figure 3b) is different from figure 2(b), which is because Tas has an obvious increasing trend. The correlation coefficients between global average NPP and Pr, Tas, and Rsds are 0.64, 0.86 and -0.01 , respectively. This means that the terrestrial ecosystem NPP has a similar change with Tas and Pr or NPP is mainly related to Tas and Pr.

\subsection{Trends in NPP}

During the past 100 years, earth has experienced dramatic environmental changes: the global average temperature has risen; $\mathrm{CO}_{2}$ concentrations have continued to rise; global warming will heat the lower atmosphere and enable it to hold more moisture, thus global water cycle has speeded up; and terrestrial ecosystem also has changed (Melillo et al. 1993; Brönnimann et al. 2008; Jones et al. 2009).

Figure 4 shows the spatial pattern of the linear trend in terrestrial ecosystem NPP between 1976 and 2005, which has an obvious increasing temporal trend almost globally except in some locations of South Africa, Australia, Mexico, and
South America. The largest increasing trend appears in the Sahel area, South Asia, and South America, mainly focused on the equatorial zone $\left(>5 \mathrm{gCm}^{-2} \bullet 100 \mathrm{yr}^{-2}\right)$. In most areas of Eurasia and North America, there is also an increase of $1-3 \mathrm{gCm}^{-2} \bullet 100 \mathrm{yr}^{-2}$.

Table 4 shows the area-averaged trend of NPP on global and regional scale. For the global scale, the trend of MME NPP is $3.901 \mathrm{gCm}^{-2} \bullet 100 \mathrm{yr}^{-2}$. The largest trend appears over $60^{\circ}-90^{\circ} \mathrm{N}$, which is larger than $4.784 \mathrm{gCm}^{-2} \bullet 100 \mathrm{yr}^{-2}$, because the Tas is increasing rapidly in this zone, which is favourable for plant growth. Generally, the trend in the northern hemisphere is larger than in the southern hemisphere, and this may be because the climate changes (such as Pr and Tas) in the northern hemisphere is stronger than in the southern hemisphere (Friedman et al. 2013).

The global IGBP NPP is $55.05 \mathrm{PgCyr}^{-1}$, and the simulated MME NPP is 50.6 $\mathrm{PgCyr}^{-1}$. For each model of our research, the simulated NPP varies from 21.46 to $74.40 \mathrm{PgCyr}^{-1}$ (not shown figures), and the difference is from -33.59 to 19.35 $\mathrm{PgCyr}^{-1}$ comparing the proxy data. NorESM1-M simulates the lowest NPP, which is almost $30 \%$ of the highest NPP from IPSL-CM5A-LR. Many studies have indicated that the global NPP ranges from 39.9 to $80.5 \mathrm{PgCyr}^{-1}$ (Cramer et al. 1999; Dan et al. 2007), which demonstrates that there is great uncertainty in simulated terrestrial ecosystem NPP. However, because of the deficiency of long term global NPP data, the modelling NPP validation is not implemented fully and maturely at global and region scales comparing the validations of climatic simulations. Maybe this means that we need to improve understanding the factors that govern the variability of NPP model estimation (Ahl et al. 2005).

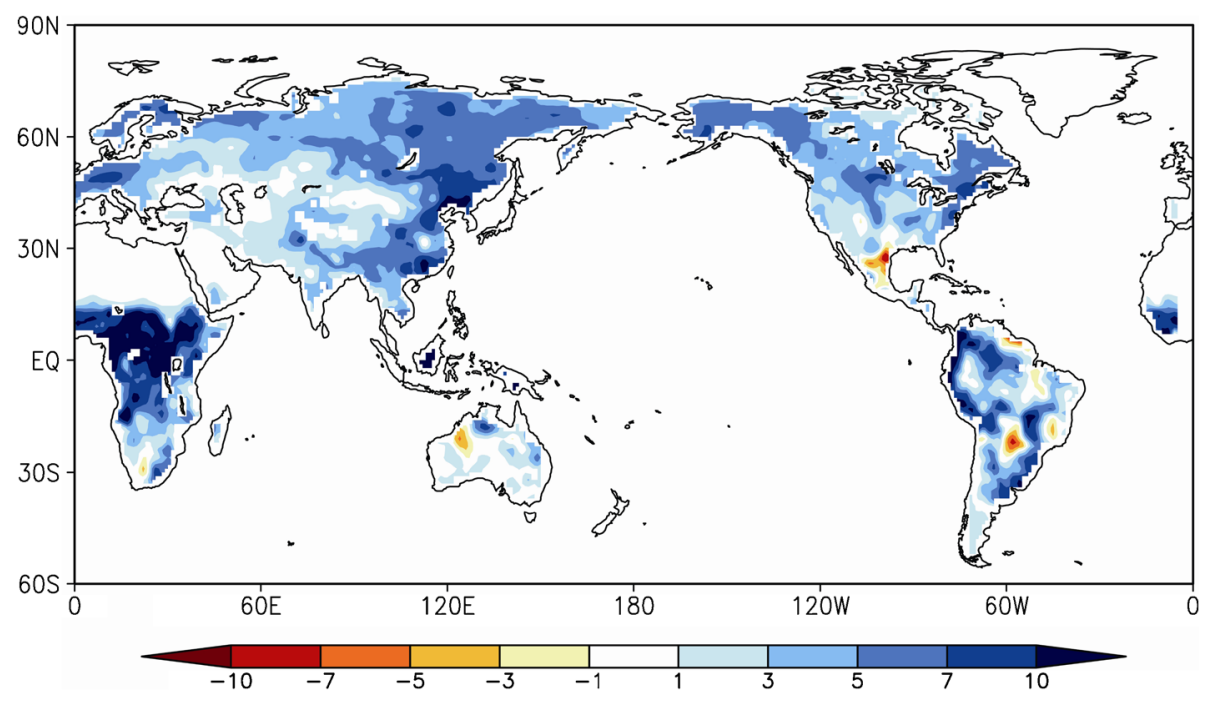

Figure 4. Trend of MME NPP, with unit of $\mathrm{gCm}^{-2} \bullet 100 \mathrm{yr}^{-1}$ during 1976-2005 over global land. 


\begin{tabular}{lcccccc} 
Table 4. Area-averaged trend of $M M E$ & $\mathrm{NPP}$, with unit of $\mathrm{gCm}^{-2} \bullet 100 \mathrm{yr}^{-2}$. \\
\hline MME NPP trend & Global & $60^{\circ}-30^{\circ} \mathrm{S}$ & $30^{\circ} \mathrm{S}-0$ & $0-30^{\circ} \mathrm{N}$ & $30^{\circ}-60^{\circ} \mathrm{N}$ & $60^{\circ}-90^{\circ} \mathrm{N}$ \\
& 3.901 & 2.624 & 3.777 & 4.119 & 3.674 & 4.784 \\
\hline
\end{tabular}

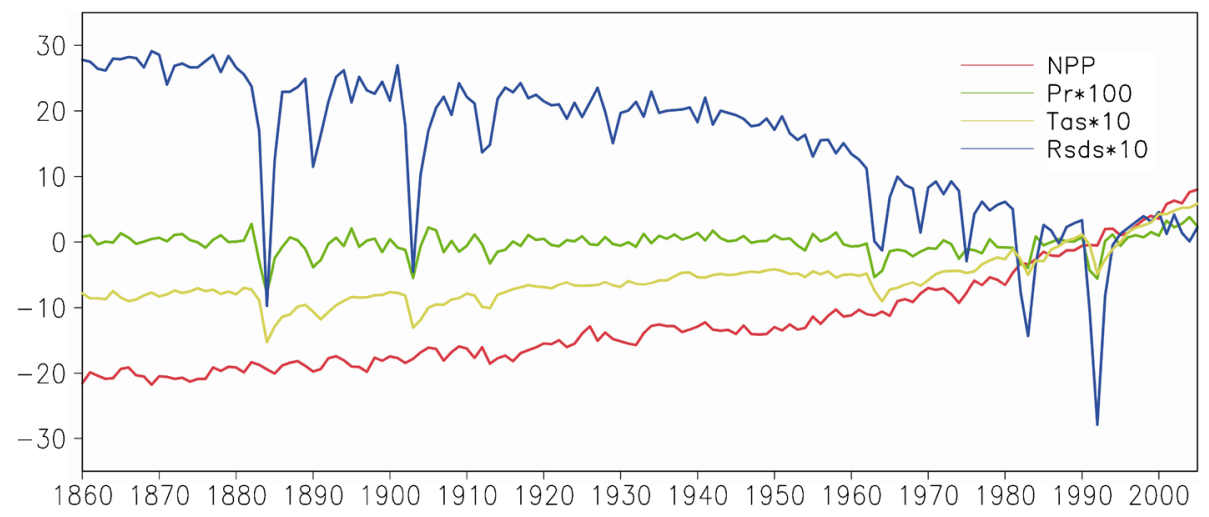

Figure 5. Long term anomaly changes of climate and terrestrial ecosystem NPP during 1860-2005 over global land, units are $\mathrm{gCm}^{-2} \mathrm{yr}^{-1} \mathrm{mmday}^{-1},{ }^{\circ} \mathrm{C}$ and $\mathrm{Wm}^{-2} \mathrm{~s}^{-1}$ for NPP, Pr*10, Tas*100 and Rsds*10, respectively.

\subsection{Long term changes of climate and terrestrial ecosystem NPP}

Figure 5 shows the interannual variation of global land MME NPP and climatic factors (Pr, Tas and Rsds) from 1860 to 2005. It is very clear that NPP has shown an increasing temporal trend in the past 150 years, and the trend from 1960 to 2005 is larger than the trend from 1860 to 1960 , which is related to the trends of climate factors. Pr shows fluctuant variation from 1860 to 1955, without an increasing trend or decreasing trend, while from 1955 to 1965 , there is a decreasing trend, and from 1965 to 2005, there is an increasing trend. Tas shows an increasing trend throughout, while Rsds always shows a decreasing trend. All the changes in the climatic factors are favourable for the changes in NPP, and it can be inferred that the terrestrial ecosystem has shown a positive response to climate change in the past 150 years. Figure 5 shows another characteristic that the Rsds is very sensitive to volcanic eruptions, and then Tas and $\mathrm{Pr}$, this is consistent with other researches (Garrison 1995; Gu and Adler 2010). Volcanic eruptions have a complex and regional effect on NPP; they enhance or diminish NPP (Krakauer and Randerson 2003); for the global annual average, the effect is limited and indirect.

\section{Conclusions}

In the present study, we first used IGBP NPP data to validate and compare the simulated global MME NPP in historical scenarios of 10 CMIP5 models. By comparing the spatial pattern at global scale, we found general consistency between MME NPP and IGBP NPP data, albeit with some differences among values.

Terrestrial ecosystem NPP is strongly related to climatic factors. Based on the present research, terrestrial ecosystem NPP has a strong correlation coefficient with Tas and Pr. For global land between 1976 and 2005, the correlation coefficients between global average NPP and Pr, Tas and Rsds are $0.64,0.86$, and -0.01 , respectively, and Pr shows a slight increase, Tas shows an obvious increase, and NPP shows an obvious increasing temporal trend.

During the past 150 years, MME NPP has increased 3.647 $\mathrm{PgC}$ during historical period, which shows an increasing temporal trend of 3.9 $\mathrm{gCm}^{-2} \bullet 100 \mathrm{yr}^{-2}$, and the terrestrial ecosystem has responded positively to climate change. The global IGBP NPP is $55.05 \mathrm{PgCyr}^{-1}$, and the simulated global MME NPP is $50.6 \mathrm{PgCyr}^{-1}$. The simulated NPP has huge uncertainty.

In reality, the terrestrial ecosystem is a complex variable, which can be effected by many factors, such as climate, $\mathrm{CO}_{2}$, human activity, and so on. It must be said that the $\mathrm{CO}_{2}$ fertilization effect is important in photosynthesis and carbon cycle calculation. In the 21 st century, the land carbon storage is expected to be enhanced by the $\mathrm{CO}_{2}$ increase but dampened by climate change (Friedlingstein et al. 2006; Shao et al. 2013). Note that $\mathrm{CO}_{2}$ concentration is prescribed for the historical simulations of CMIP5 and there is no feedback. In the present paper, we have only discussed climatologic effects. However, the terrestrial ecosystem is also related strongly with vegetation type, but the 
problem is we are unable to get vegetation maps for all the models, which causes some limitations on our research.

\section{Acknowledgements}

This work has been financially supported by the National Natural Science Foundation of China (41205076), the National Basic Research Program of China (2013CB956004 and 2010CB950503), the Hundred Talents Program of the Chinese Academy of Sciences (51Y251551), and the West Light Foundation of the Chinese Academy of Sciences (29Y128871). Authors thank Prof. Stefan Hagemann and ISLSCP II for providing the MPI LAI data and IGBP NPP data.

\section{References}

Ahl D E, Gower S T, Mackay D S, Burrows S N, Norman J M and Diak G R 2005 The effects of aggregated land cover data on estimating NPP in northern Wisconsin; Remote Sens. Environ. 97(1) 1-14.

Arora V, Scinocca J, Boer G, Christian J, Denman K, Flato G, Kharin V, Lee W and Merryfield W 2011 Carbon emission limits required to satisfy future representative concentration pathways of greenhouse gases; Geophys. Res. Lett. 38(5).

Bala G, Joshi J, Chaturvedi R K, Gangamani H V, Hashimoto H and Nemani R 2013 Trends and variability of AVHRR-derived NPP in India; Remote Sens. 5(2) 810-829.

Brönnimann S, Diaz H F, Ewen T, Luterbacher J, Neu U and Stolarski R S 2008 Climate variability and extremes during the past 100 years; Springer.

Cao M, Prince S D, Small J and Goetz S J 2004 Remotely sensed interannual variations and trends in terrestrial net primary productivity 1981-2000; Ecosystems 7(3) 233-242.

Collins W, Bellouin N, Doutriaux-Boucher M, Gedney N, Halloran P, Hinton T, Hughes J, Jones C, Joshi M and Liddicoat S 2011 Development and evaluation of an Earth-system model-HadGEM2; Geoscientific Model Development Discussions 4(2) 997-1062.

Cramer W, Kicklighter D, Bondeau A, Iii B M, Churkina G, Nemry B, Ruimy A and Schloss A 1999 Comparing global models of terrestrial net primary productivity (NPP): Overview and key results; Global Change Biology 5(S1) $1-15$.

Dan L, Ji J and He Y 2007 Use of ISLSCP II data to intercompare and validate the terrestrial net primary production in a land surface model coupled to a general circulation model; J. Geophys. Res.: Atmospheres 112(D2) 1984-2012.

Dan L, Ji J and Li Y 2005 Climatic and biological simulations in a two-way coupled atmosphere-biosphere model (CABM); Global Planet Change 47(2) 153-169.

Dufresne J-L, Foujols M-A, Denvil S, Caubel A, Marti O, Aumont O, Balkanski Y, Bekki S, Bellenger $\mathrm{H}$ and Benshila R 2013 Climate change projections using the IPSL-CM5 Earth System Model: From CMIP3 to CMIP5; Clim. Dyn. 40(9-10) 2123-2165.
Friedlingstein P, Cox P, Betts R, Bopp L, Von Bloh W, Brovkin V, Cadule P, Doney S, Eby M and Fung I 2006 Climate-carbon cycle feedback analysis: Results from the C4 MIP Model Intercomparison; J. Climate 19(14) 3337-3353.

Friedman A R, Hwang Y-T, Chiang J C and Frierson D M 2013 Interhemispheric temperature asymmetry over the Twentieth Century and in future projections; J. Climate 26(15) 5419-5433.

Garrison J 1995 An evaluation of the effect of volcanic eruption on the solar radiation at six Canadian stations; Solar Energy 55(6) 513-525.

Gent P R, Danabasoglu G, Donner L J, Holland M M, Hunke E C, Jayne S R, Lawrence D M, Neale R B, Rasch P J and Vertenstein M 2011 The Community Climate System Model, Version 4; J. Climate 24(19).

Gu G and Adler R F 2010 Precipitation and temperature variations on the interannual time scale: Assessing the impact of ENSO and volcanic eruptions; J. Climate 24(9) 2258-2270.

He Y, Dan L, Dong W, Ji J and Qin D 2005 The terrestrial NPP simulations in China since last glacial maximum; Chinese Sci. Bull. 50(18) 2074-2079.

Ito A and Oikawa T 2000 A model analysis of the relationship between climate perturbations and carbon budget anomalies in global terrestrial ecosystems: 1970 to 1997 ; Clim. Res. 15(3) 161-183.

Jones C, Lowe J, Liddicoat S and Betts R 2009 Committed terrestrial ecosystem changes due to climate change; Nature Geosci. 2(7) 484-487.

Kicklighter D, Bondeau A, Schloss A, Kaduk J and Mcguire A et al. 1999 Comparing global models of terrestrial net primary productivity (NPP): Global pattern and differentiation by major biomes; Global Change Biology $\mathbf{5 ( S 1 )}$ 16-24.

Krakauer N Y and Randerson J T 2003 Do volcanic eruptions enhance or diminish net primary production? Evidence from tree rings; Global Biogeochemical Cycles 17(4) 1118-1129.

Lindsay K, Bonan G, Doney S, Hoffman F, Lawrence D, Long M, Mahowald N, Moore J, Randerson J and Thornton P 2014 Pre-industrial control and 20th century carbon cycle experiments with the earth system model CESM1 (BGC); J. Climate 27(24) 8981-9005.

Melillo J M, Mcguire A D, Kicklighter D W, Moore B, Vorosmarty C J and Schloss A L 1993 Global climate change and terrestrial net primary production; Nature 363(6426) 234-240.

Nemani R, White M, Thornton P, Nishida K, Reddy S, Jenkins J and Running S 2002 Recent trends in hydrologic balance have enhanced the terrestrial carbon sink in the United States; Geophys. Res. Lett. 29(10) 106-1-106-4.

Nemani R R, Keeling C D, Hashimoto H, Jolly W M, Piper S C, Tucker C J, Myneni R B and Running S W 2003 Climate-driven increases in global terrestrial net primary production from 1982 to 1999; Science 300(5625) 15601563.

Olofsson J and Hickler T 2008 Effects of human land-use on the global carbon cycle during the last 6000 years; Vegetation History and Archaeobotany 17(5) 605-615.

Runing S, Baldocchi D, Turner D, Gower S, Bakwin P and Hibbard K 1999 A global terrestrial monitoring network integrating tower fluxes, flask sampling, ecosystem modeling and EOS satellite data; Remote Sens. Environ. 70 108-127.

Shao P, Zeng X, Sakaguchi K, Monson R K and Zeng X 2013 Terrestrial carbon cycle: Climate relations in eight CMIP5 Earth System Models; J. Climate 26(22) 87448764 . 
Sitch S, Smith B, Prentice I C, Arneth A, Bondeau A, Cramer W, Kaplan J, Levis S, Lucht W and Sykes M T 2003 Evaluation of ecosystem dynamics, plant geography and terrestrial carbon cycling in the LPJ dynamic global vegetation model; Global Change Biology 9(2) 161-185.

Taylor R K E, Stouffer R J and Meehl G A 2012 An overview of CMIP5 and the experiment design; Bull. Am. Meteorol. Soc. 93 485-498.

Tjiputra J, Roelandt C, Bentsen M, Lawrence D, Lorentzen $\mathrm{T}$ and Schwinger J 2012 Evaluation of the carbon cycle components in the Norwegian Earth System Model (NorESM); Geoscientific Model Development Discussions 5(4) 3035-3087.

Wang S, Zhang M, Li Z, Wang F, Li H, Li Y and Huang X 2011 Glacier area variation and climate change in the Chinese Tianshan Mountains since 1960; J. Geogr. Sci. 21(2) 263-273.
Watanabe S, Hajima T, Sudo K, Nagashima T, Takemura T, Okajima H, Nozawa T, Kawase H, Abe M and Yokohata T 2011 MIROC-ESM: Model description and basic results of CMIP5-20c3m experiments; Geoscientific Model Development Discussions 4(2) 1063-1128.

Wu Q, Feng J, Dong W, Wang L, Ji D and Chen H 2013a Introducion of the CMIP5 experiments carried out by BNU-ESM; Progressus Inquisitiones de Mutation Climatis 9(4) 291-294.

Wu T, Li W, Ji J, Xin X, Li L, Wang Z, Zhang Y, Li J, Zhang $\mathrm{F}$ and Wei M 2013b Global carbon budgets simulated by the Beijing Climate Center Climate System Model for the last century; J. Geophys. Res.: Atmospheres 118(10) 4326-4347.

Wu T, Song L, Li W, Wang Z, Zhang H, Xin X, Zhang Y, Zhang L and Li J 2013c An overview of BCC climate system model development and application for climate change studies; J. Meteorol. Res. 28(1) 34-56. 